\title{
A holistic exploration of leadership development
}

\author{
B. von Krosigk* \\ Department of Psychology, University of South Africa, \\ PO Box 392, Pretoria 0003, Republic of South Africa \\ VKROSBC@unisa.ac.za]
}

Received July 2006

\begin{abstract}
Aligning body, mind and spirit, acquiring emotional intelligence, an unshakable belief in their own intuition and producing outcomes in the context of organisational abilities encompass the attributes of leaders that emerged from this holistic exploration of leadership development. Emotionally aware leaders demonstrated their authenticity and cared for peaceful process. In this exploration such leaders started at the bottom within their enterprise working their way up over time. Agreeableness and flexibility were the core competencies they developed amongst others. A complex mix of behaviour, thoughts and emotions were the specific leadership attributes that were found to differ for different organisations. These specific leadership attributes needed to fit with the character and dynamics of the organisation. Since leadership development was found to be a holistic character development over time leadership courses are recommended for all scholars and students, with a strong emphasis on self-development. A grounded theory approach to this holistic exploration of leadership development serves the community well, by promoting the emergence of grounded theories which are free from practical impossibilities.
\end{abstract}

*To whom all correspondence should be addressed.

\section{Introduction}

He who knows himself and others,

Will also recognise now:

East and West can no longer remain separate. Goethe (translated by B. von Krosigk)

In post-apartheid South Africa, Nelson Mandela has become an example to the world as a leader who has effected peaceful change. His behaviour is of a kind that the world has rarely witnessed in the last 2600 years, and despite having spent 27 years in prison, his decision to forgive and to refrain from retribution, are the most unusual undertakings he has launched (Von Krosigk, 2000). Combinations of his conduct and character have achieved what others were unwilling or incapable of achieving (Mandela, 1997). His personal commitment to achieving a peaceful transformation has evoked admiration, respect and endearment from people all over the world. The unusual combination of his outstanding characteristics, such as his highly developed self, his forgiving stance, his fairness and caring attitude are very similar to the character traits of exceptional leaders of the past. By divesting himself of everything negative, displayed during the times of his political struggle, such as aggression, authoritarianism, anger and agitation, Mandela achieved the amazing comportment of a humane and compassionate president and leader in a post-apartheid South Africa (Mandela, 1997).

What is valued and searched for in leaders encompasses the traits that Mandela has acquired during the time of his imprisonment. He became what Lao Tzu, the Chinese philosopher from the sixth century BC recommended as necessary for an effective leader of an organisation, kingdom, government, and community. Lao Tzu (600 BC) recommends that characteristics cultivated by those in positions of leadership, should be the acquisition of an undistorted reality, integrity and insight. This means that knowledge of the things in the world as well as selfknowledge needs to be acquired for wisdom to develop (Jung, 1990). In addition to that, individuals in positions of leadership need to avoid behaviour that suggests aggressiveness or conflict in order to prevent counterreactions that might disturb their peaceful ruling and their tranquil, peaceful self (Jung, 1933; Jung, 1990; Lao Tzu, 600 BC; Robinson, 1990).

In order to heal a broken world, the starting point should be the divided self, which according to Jung (1933) is the spiritual problem of modern man. According to Scheibe (1995), healing and transforming the inner-self should be the aim of every potential leader. Only those who have harnessed the self-serving force of their own ego can hope to support those with oversized egos. Only those who have mastered humility and the understanding that nothing can exist in this world without the support of other individuals, animals, plants and minerals can prevent those with an exaggerated sense of self-importance from falling flat onto their faces more often than not. Negative attitudes can be toxic for one's own health and can develop hostility in others in interpersonal relationships (Von Krosigk, 2000). Intelligence needs to be applied in order to achieve a benign attitude towards the world, the self and others.

Rumi (1988) identifies two kinds of intelligence: the kind that is acquired at school, according to which we are ranked ahead or behind our peers, and the kind that is already completed inside us, which is our fluid fountainhead, 
moving out from within. According to Jung (1990), the fluid second kind of intelligence can also be called the united self, which is the state that we achieve when our body, mind and spirit are united. The source of true leaders according to Lao Tzu (600 BC) emanates from within. The fluid fountainhead of effective leaders according to Rumi (1988) can thus be understood as the driving force behind their humility and wisdom, which is a natural consequence of the alignment between their body, mind and spirit.

Another kind of intelligence that has recently become the focus of attention for effective interpersonal behaviour according to Cameron-Bandler and Lebeau (1986), Goleman (2000) and Goleman (2004) is emotional intelligence. In the context of leadership development, emotional intelligence can be added to the two kinds of intelligence identified by Rumi as a necessary attribute of effective leaders. Inspiring others is an important task of a leader, and good leaders are distinguished by their ability to inspire others without receiving negative feedback in the form of resistance to perform. Good leaders are skilled in motivating and encouraging others, which means they need to be emotionally aware of what goes on in other people's minds. Bass (1990), Kouzes and Posner (1995; 1993), Posner and Schmidt (1992) and Schmidt and Posner (1982) refer to the importance of leader traits such as credibility, integrity, honesty and fair-mindedness for effective leadership. Whether these traits were observed by employees who only see their leader from afar or by close associates of leaders who are able to observe their leader in decision-making processes was unfortunately not clearly explained.

The choice of leaders who participated in this study was made by means of purposive sampling according to Denzin and Lincoln (2000) and Rubin and Babbie (2001), which means that I approached twelve leaders from an unknown number of leaders whom I had met either by introduction or by referral over a time span of thirty years, requesting each one for a lengthy interview. In the end, the ten leaders that fit the 'effective' leadership criteria, as will be explained below, were extracted for this discussion. The sample of the ten effective leaders consisted of two females and eight males, of which eight were light-skinned Europeans while two, were different shades of brown-skinned Africans. The investigation took place in South Africa, Germany and Australia.

The study on which this article is based was conducted with the intent of finding the maximum amount of essential attributes, qualities or traits that occur in effective leaders. Leader effectiveness in this study was based on the way outcomes are produced by using the capabilities within an organisation. This was achieved by interviewing the leaders, one or two peers and one or two subordinates. Firstly, the information from their stories was placed into categories of leadership traits that were shown (by the information gained from the leaders', peers' and subordinates' interviews) to produce the intended positive outcomes, and secondly, the way in which these positive outcomes were achieved within the organisational structure.

The process of interviewing occurred over a period of 6 years, from 2000 until 2005 after which ten effective leaders were drawn from the pool of interviewees for inclusion in this holistic description of leadership development.

The assumptions that were made with regard to the acquisition of leadership attributes are based on my lifelong observations on leadership characteristics in diverse situations. I thus assumed that leadership attributes were possibly already present during the childhood years, and that at least some leaders could have been aware of such qualities within themselves at an early age. Secondly, I assumed that leadership qualities could possibly be complexly interwoven with the development of a person, and that a holistic investigation would be necessary to uncover the complex ability of leadership effectiveness.

An effective systematic search for unique individual experiences was therefore implemented with the aim of uncovering attitudes, values, likes, dislikes, natural affinities, ideas, feelings and responses to events, people, places and situations throughout an individual's life. This investigation was achieved by asking twelve leaders to tell their stories with regard to their leadership position, and by uncovering historical decision-making processes with regard to their choices that lead to their appointment as leaders. This encompassing approach to describe effective leaders can contribute to the body of leadership knowledge and serve as a model for the silent, imperceptible development of future leaders.

My request for researching poorly understood attributes of leadership development was regarded as important and all leaders who were approached agreed to tell their stories. The leaders all chose their preferred place and time, and subsequently all interviews were conducted in their offices in the late afternoon ensuring no interruptions throughout the interview. The leaders were therefore relaxed and open to recounting the ramifications of their lives that had propelled them into leadership positions.

An unstructured interviewing format was applied throughout the research project. This served as a way of opening up new information on leadership issues for the unknown explorative journey, the essence of grounded theory research (Glaser \& Strauss, 1967; Strauss \& Corbin, 1990). The unstructured interviewing format also allowed for exploring the leaders' reasons for certain behaviours, thoughts and feelings in a particular context. This strategy was chosen with the aim of remaining an unbiased observer/listener as well as allowing the leaders to present their authentic thoughts. The unstructured interviewing format further contributed to accurate reproductions of the leaders' authentic stories without having to make any interpretations (Von Krosigk, 2000; 2004). All leaders were assured of confidentiality and anonymity with regard to the disclosed information, which was appreciated by eight of the leaders, while the remaining two did not mind being named.

The data was collected by means of making some notes, and by committing the story with its feelings, thoughts, and behaviours to memory. Each story was written down and returned to the leaders, who were then requested to verify/correct the written accounts of their story. This served to ensure that the data that had been gathered during the 
interview was true to each leader's intentions. The information with regard to leadership development was extracted from the leaders' stories and organised into three groups, a) The complexity of becoming a leader, b) The complexity of being a leader, and c) The effects of being a leader. The development of becoming a leader could not be clearly separated from being a leader, which in turn could not be clearly separated from the effects of being a leader, because reciprocal feedback loops linked the three processes throughout the lifespan of each individual leader (Becvar \& Becvar, 1996). E.g. the effects of being a leader informed the self-reflexive leader of how to adapt his/her behaviour, thoughts and feelings in order to become and be a better, more effective leader. According to Bar-On (1996) selfreflexivity is one of the intra-personal attributes of emotionally intelligent beings, which amongst other attributes such as assertiveness, self actualisation and independence form one level of emotional awareness which is in constant reciprocal interaction with the inter-personal level in inter-personal relationships characterised by empathy and social responsibility. The intra- and interpersonal levels in turn are in constant reciprocal interaction with the cognitive level (problem solving, reality testing and flexibility), the self management aspect (stress tolerance, stress management and impulse control) and the emotional component (happiness and optimism) of an emotionally intelligent being. Covey's (1989) explanation of what is understood by being effective can be added to this complexly interwoven, reciprocally interactive process on the intra-personal, inter-personal, cognitive, self management and emotional level in order to appreciate the complexity, inseparability and developmentally cumulative process of acquiring positive and negative character traits. The acquisition of positive character traits and how this process of development occurred throughout the lifetime of people who are identified as effective leaders on the grounds of being proactive, considering the big picture when attending to the details, prioritising, thinking win/win, asking questions in order to understand, synergising and incorporating their gut feeling, lies at the core of this investigation.

\section{Results}

\section{The complexity of becoming a leader}

Leadership seems to be a complex concept, and different ways of becoming a leader can be observed. Some leaders seem to be mysteriously prepared behind the scenes for decades, like Nelson Mandela, while others are hand-picked in early childhood and groomed for the task, like the Dalai Lama. What all great leaders do however have in common, is that they are truly who they are meant to be, by being true to themselves, and by living their own life (Bass, 1990; Mandela, 1997). Some of these complexly interwoven characteristics were revealed by all ten leaders in different combinations.

According to Lao Tzu (600 BC) leaders are sometimes chosen by someone else to be a leader. A typical occurrence for great leaders of the past is that they seem to have come from humble roots, and from our perspective seem to rise suddenly like a rare phenomenon in the sky (Yukl, 2002).
Six of the ten leaders in the research group came from humble roots, rising far above the level of their origins.

In the past, people who emerged as great leaders have spent most of their time developing their self by learning everything that was presented to them during the course of their life (Burns, 1978; Fisher, Rooke \& Torbert, 2000; Lao Tzu, 600 BC; Mandela, 1997). According to Bruner (1990) and Goleman (2004) they acquired integrity by getting to know themselves through constant reflection and a thorough understanding of others through positive interactions and clear communication. Interacting with integrity with others opens the world in all its multifaceted attire (Von Krosigk, 2000). Learning about others expands our knowledge and understanding of the world on all levels and in all areas, and leads to an appreciation of that which is different (Goleman, 2004; Torbert, 1991). Appreciating that which is different challenges the acceptable norms of the society of which one is a part (Schlenker \& Darby, 1981). These new perspectives lead to deeper insight into the behaviour, beliefs and traditions of others (Kanungo \& Mendonca, 1996). It also leads one to question one's own behaviour and beliefs. By comparing one's own way of doing to the way others are doing something one may realise that both ways get the job done equally well (Schlenker \& Darby, 1981). This realisation leads to openness with regard to one's own way of doing something as being only one of many alternatives for getting the job done (Yukl, 2002). Delegation of tasks thus becomes easy, and the dynamics of interpersonal relationships are more motivated on account of working together effectively and efficiently rather than performing for the sake of glory, power, or one-up-man-ship (Trevino, Brown \& Hartman, 2003).

All ten leaders demonstrated a clear understanding of themselves and others. The acquisition of integrity was a result of this understanding. The hallmark of all ten leaders was an appreciation for that which is different. One leader in particular only employed those who were different to him/herself, and another enjoyed communicating with people who held different views to his/her own.

Moreover, in the course of their lives, all ten leaders had been exposed to a number of different traditions, values and beliefs. Therefore all had come to the crossroads of questioning their own behaviour and beliefs, while six out of the ten leaders had taken steps to change their own behaviour successfully.

In addition, eight of the leaders who were interviewed demonstrated great flexibility by allowing others to do the job in a way that was most comfortable for the one who was asked to perform that particular job, and they all reiterated that getting the job done was all that counts.

Positive self-talk, as an instrument of self-correction was applied by eight of the ten leaders who were interviewed, and power, glory and one-up-man-ship were subsequently non-existent in these leaders' vocabulary and self-talk. They all strove towards getting results (financial and otherwise) for their firm, business or institution. Three referred to themselves as the ones who were there to take all the flack so that others could devote their energy to performing their 
work effectively. Negotiating with difficult people was one of the unique strengths of eight out of the ten leaders in the research group, which freed others to get the job done. Leadership development in all ten leaders was found to be a complexly interwoven learning experience throughout their lives on the individual, social, environmental, spiritual and physical levels.

Eight of the ten leaders conducted their interpersonal relationships in a companionable and cooperative style, and working together for the benefit of all concerned was the characteristic they had developed from experiencing a variety of encounters in diverse contexts, such as sport, studies, hobbies, home and work.

Nine leaders began to tell their story in the same way, namely by referring to their childhood. Eight reported that they realised around the age of six that they had leadership abilities. These leaders were first born or only children. One only realised that he/she had leadership abilities around the age of 40. It did however become clear from this leader's life story that he/she had engaged in leading others within a democratic context throughout his/her lifetime.

One leader who grew up as the youngest child within a family of leaders did not know he/she had leadership ability until he/she was thrust into a leadership position. His/her leadership ability was mainly of an unconscious nature, which was displayed as an unconscious competence on a number of levels of functioning.

\section{The complexity of being a leader}

Having received and developed the gift of leadership, great leaders then present their followers with the gifts of developing the unique potential of the people they lead (Bass \& Steidlmeier, 1999; Trevino et al., 2003).

All ten leaders in the research group derived great pleasure from developing the innate potential of others.

When a leader focuses on the goal, such as getting a particular job done, the focus will be on positive interactions with those who have the specialised skills and knowledge that contribute towards attaining that goal (Rosenwald \& Ochberg, 1992). A leader thus assesses the skills of others accurately in order to make the best distribution of individual contributions towards attaining the goal.

Six out of the ten leaders in the group were able to assess the skills of others accurately (they said they have seldom or never been wrong), while the other four admitted to being grateful for the availability of projective tests that could assist them in that regard because they had repeatedly chosen individuals who had presented themselves as competent and knowing, but failed in delivering and applying themselves.

Everyone is valued for their unique contribution, and by accepting others with their strengths and weaknesses, an appreciation for the uniqueness of others is born (Yukl, 2002).
Nine of the ten leaders interviewed valued the uniqueness of others while the one who did not, admitted that he/she felt threatened by others' uniqueness, because it made it difficult for him/her to predict their behaviour.

The possibility does however exist that, although a leader may have all the right attributes, he/she may still fail to lead the people effectively according to Kouzes and Posner (1993).

This dynamic is seldom researched and easily ignored, because of the intangibility of the process within a particular context. One leader however offered a very candid glimpse of precisely this dynamic. He/she demonstrated all the right attributes of a leader, yet in his/her own eyes failed to lead his/her people effectively. He/she admitted to being suspicious by nature and unable to trust others. His/her peers however, viewed this leader as a kind, effective leader, whose compassionate nature was often taken advantage of by new employees, who deceived and schemed to gain as much as they could without concern for others, resulting in their dismissal.

The time-pressure by which most leaders from large corporations are restrained in order to optimise efficiency and effectiveness, often does not allow for investigations that comprise the telling of stories with the aim of uncovering historical decision-making processes.

The study, on which this article is based, however revealed that the telling of stories is a very effective way of understanding the effectiveness and the ineffectiveness of leaders and/or followers. The suspicious leader who is unable to trust was also unable to assess his / her own and others' intentions accurately. He/she therefore failed to understand why the creative force in his/her subordinates and peers was hampered.

Leadership research seldom takes into consideration whether leaders have been chosen by their followers or whether they were appointed by their superiors (Rosenwald \& Ochberg, 1992). Leaders who are loved by their followers seem to stand out with regard to positive leadership qualities (Conover, 1982). According to Mallonee (1976), leaders, who are either disliked or simply obeyed by their followers, seem to be regarded as restraining, unapproachable, selfserving and unwilling to facilitate open discussions. This difference has been noticed, but the qualities of the followers have unfortunately not been taken into account. To be a leader of followers who themselves are leaders, could pose different challenges. Leaders, who were selected as a figurehead that could be easily manipulated would again create a different dynamic to those who were selected for their positive leadership qualities.

In the study on which this article is based, eight leaders had been chosen by their superiors, one was self-appointed and one chosen by his/her peers. More interviews with a larger number of followers would however be necessary for commenting in this regard. 


\section{The effects of being a leader}

Thinking strategically, establishing direction, having a vision for the future, leading change and driving value creation are not the only attributes of effective leaders. Soft skills, such as engaging with and inspiring others, being emotionally sensitive with regard to different cultures and religions have made great inroads on leadership training courses. Successful leaders tend to be most able to exhibit these soft skills.

Leadership attributes in mature leaders from this investigation were found to be tied up with personality traits, the development of which varied with regard to the family dynamics within their families of origin. It thus seems that some leaders tend to emerge from problematic family backgrounds, which honed their conscious coping skills, sometimes at a very young age. These skills included self-sufficiency and taking care of others. These leaders also had to learn to deal with crises and uncertainty early in their lives. Some were subjected to upheaval, domestic relocations and adjusting to new circumstances, people, schools and infrastructures several times. Defective mothers were often referred to as the factor necessitating selfsufficiency and emotional sensitivity.

The outstanding trait common to all leaders was their intolerance to working in untidy or chaotic circumstances, which elicited their wish and motivation for creating and maintaining order. Efficiency and order were the two most common aspects of being motivated for or having the desire to run or lead an enterprise. Even those who termed themselves "reluctant" leaders, because"there was no one else available to lead the company", were order and efficiency conscious.

The most emotionally aware leaders from this study were also aware of the world around them. They demonstrated authenticity and displayed a collaborative individualism. They also balanced business and community interests and cared for outcomes as much as for peaceful process. Such leaders were found amongst those who had started at the bottom within their company by working themselves up towards the top as time passed by. Their knowledge of the company environment and climate made it easy for them to fit in and to continue to uphold the values and expectations of its employees and clients. These leaders considered themselves dependable but academically underachieving during their school years. They enjoyed interacting with others and also liked to accomplish things on their own. All ten leaders were open to new ideas, suggestions or experiences, and they were keen on improving themselves as they learnt about their minor deficiencies. Leadership effectiveness was extremely important to all of them, and they professed to isolate themselves socially deliberately with the intent of remaining objective and fair to all concerned. They did however engage in official socialising activities to establish social trust. Flexibility and agreeableness were high on their list of competencies and a willingness to adjust to different cultures and different contexts marked their mutually positive interactions with foreigners. These emotionally aware leaders were at least bilingual. A certain degree of detachment was evident in these leaders with regard to their interactions at work. Only some of these leaders extended personal invitations to their subordinates for fear of losing their objectivity and sense of fairness towards the company's employees. They were also highly aware of the possibility of being accused of nepotism, and thus avoided socialising with their employees. They also refrained from hiring family members and friends.

For eight of the ten leaders spending a few minutes on their own in prayer, meditation or going for a solitary walk/run on a regular basis was an extremely important aspect of their effective functioning. Some confessed to having made less and less time for a solitary convergence of thoughts with resultant negative consequences, such as a lowered degree of self-assurance.

With regard to five leaders who were interviewed, there was a small divergence of the leadership styles amongst the leaders in this study. They felt that a particular leadership style is correlated to the interpersonal dynamics within the organisation and the vision, goals and mission of that organisation. This observation was confirmed by the other five leaders who mentioned that a goodness of fit between leader and enterprise is important for effectiveness in the workplace. This point was underscored by the fact that when organisational transformation became necessary in several organisations, the leadership role in some organisations was filled by outsiders who entered as objective consultants or change agents. The impersonal touch of these 'intruding leaders' was often a very negative experience to those who had worked in the organisation all their life. Lacking trustworthiness and neglecting old values, patterns, routines, hierarchies and expectations for promotion and service excellence were often overthrown and pushed aside by such change agents, which in turn tended to antagonise the very people whose cooperation they needed for change to occur. Trustworthiness thus emerged as the cornerstone of effective leadership during times of organisational transformations.

It was also found that changing times seem to impact on the need to exchange organisational leaders on a more regular basis. Some leaders in this study agreed that in today's climate, change of leadership is imperative after a certain number of years (between three to five) or when they felt they could not contribute anything new any longer.

All ten leaders considered strategic innovation as the most effective and profitable exercise for achieving a changed corporate mind-set. A positive attitude in most employees towards personal change was thus a high priority for each leader in his/her respective organisation, although only eight leaders claimed that in their organisation a positive mind-set had been attained in most employees, by way of personally interacting with their employees and receiving feedback .

It takes a long time to build trust, and only one instant to destroy it (Goleman, 2004; Bass, 1990).

Trust stood out as one of the core attributes that all the leaders in this study considered extremely important for effective leadership. Eight achieved to build trust with their followers while two are striving to do so with varying degrees of success. 
According to the ten leaders in the research group, different organisations require specific sets of leadership competencies, and the effects of these interacting variables are expressed as actions or behaviour. The complex interactions between personal, social, and cognitive competencies, knowledge, self-image, values, attitudes, needs, emotions, defences, motives and traits make each leader a uniquely assembled bundle of energy intent on making a success within their unique organisation in the context of today's global market. All leaders recognised the need to achieve a goodness of fit between a specific organisation and its leader if both were to be successful and mutually beneficial for each other.

\section{Conclusion}

The holistic exploration of leadership development uncovered leaders as complex people. On the one hand they seem to be people-oriented and on the other hand they display the attributes of loners. They also seem to experience themselves as academic underachievers, yet achieve miracles when called to negotiate in difficult situations. These paradoxical findings in the world of eight leaders from this research group seem to echo their childhood years during which they inadvertently gained independence much earlier than their peers. The early development of emotional intelligence in these leaders influenced by their early recognition of having leadership ability could have possibly contributed towards the selfconfessed academic underachievement of seven leaders, since they 'practiced' leading others on the sports field and other extracurricular activities rather than spending time behind their desks studying. For some, carrying the burden of parental inadequacy and the responsibility of having to care for themselves at an early age in an environment without support structures and adults to consult with, may have contributed to their interrupted, unstructured learning efforts in emotionally draining home environments. This state of affairs could have contributed to an accelerated learning of emotional intelligence, while forfeiting adequate progress in the required scholastic requirements. Viewed within the context of the time in which these leaders were raised, school discipline and social structures may have also played a role in the development of personal responsibility for taking control of their own lives. The tendency to sacrifice themselves for achieving common goals or for the betterment of humankind was found in nine leaders, because according to their own reasoning, they already learnt to make sacrifices in early childhood. All the above factors could have contributed to the development of leadership attributes in the leaders who were interviewed in this study.

The implication of the above findings seems to challenge the current belief that leadership development courses should be aimed at high academic achievers at school. According to Goleman (2004), Rorty (1999), Kouzes and Posner (1995), Kouzes and Posner (1993), Posner and Schmidt (1992), Jung (1990; 1950), Bass (1990), Cameron-Bandler and Lebeau (1986), Schmidt and Posner (1982), Rumi (12071273 ) and Lao Tzu (600BC) knowledge of the things in the world such as an undistorted reality, insight, understanding and self-knowledge such as integrity, vision, intuition, commitment and emotional awareness need to be acquired for wisdom to develop.

It therefore follows that leadership courses need to be aimed at all school going children. In order to equip future leaders and followers with the development of essential qualities for a humane and compassionate leadership and follower praxis, all children need to be exposed to emotionally intelligent role models. Child, as well as adult bullies usually lack interpersonal skills and subsequently cause unnecessary stress at school and in the workplace poisoning the environment and resulting in lowered productivity. In the light of an ever increasing significance for the necessary acquisition of emotional intelligence and control of our own life in the light of entrepreneurship, peace in the workplace and successful self-management can be achieved when we have all developed ourselves adequately in the area of emotional intelligence and interpersonal skills in conjunction with an unshakable belief in our own intuition.

\section{References}

Bar-On, R. 1996. 'The era of the 'EQ': Defining and assessing emotional intelligence'. Poster session at the $104^{\text {th }}$ Annual Convention of the American Psychological Association in Toronto on $9^{\text {th }}$ August 1996.

Bass, B.M. 1990. Bass and Stodgill's handbook of leadership. $3^{\text {rd }}$ Edition. New York: The Free Press.

Bass, B.M. \& Steidlmeier, P. 1999. 'Ethics, character, and authentic transformational leadership behavior', Leadership Quarterly, 10(2):181-218.

Becvar, D.S. \& Becvar, R.J. 1996. Family therapy: A systemic integration. $3^{\text {rd }}$ Edition. Massachusetts: Simon and Schuster.

Brulin, G. 2001. 'The third task of universities or how to get universities to serve their communities!' In Reason, P. \& Bradbury, H. (Eds.). Handbook of action research. London: Sage.

Bruner, J. 1990. Acts of meaning. Cambridge: Harvard University Press.

Burns, J.M. 1978. Leadership. New York: Harper\&Row.

Cameron-Bandler, L. \& Lebeau, M. 1986. The emotional hostage. San Rafael: Future Pace.

Conover, H.H. 1982. Business dynamics. Indianapolis: Bobbs Merrill Educational.

Covey, S.R. 1989. The 7 habits of highly effective people. London: Simon \& Schuster UK Ltd.

Denzin, N.K. \& Lincoln, Y.S. 2000. Handbook of qualitative research. London: Sage

Fisher, D., Rooke, D. \& Torbert, W.R. 2000. Personal and organizational transformation: Through Action Inquiry. Revised edition. Boston, MA: Edge/Work Press. 
Glaser, B. \& Strauss, A.L. 1967. The discovery of grounded theory. New York: Aldine.

Goleman, D. 2000. 'Leadership that gets results', Harvard Business Review, March-April 2000 .78(2):78-90.

Goleman, D. 2004. Emotional intelligence: Why it can matter more than IQ and working with emotional intelligence. London: Bloomsbury.

House, R.J. \& Aditya, R.N. 1997. 'The social scientific study of leadership: Quo vadis?' Journal of Management, 23: 409-473.

Jung, C.G. 1933. 'Spiritual problem of modern man.' In Fabozzi, P.F. 2002. Artists, critics, context: readings in and around American art since 1945. Upper Saddle River, N.J.: Prentice Hall.

Jung, C.G. 1990. The basic writings of C.G.Jung. Princeton, N.J.: Princeton University Press.

Kanungo, R.N. \& Mendonca, M. 1996. Ethical dimensions of leadership. Thousand Oaks, CA: Sage.

Kouzes, J.M. \& Posner, B.Z. 1993. Credibility. San Francisco: Jossey-Bass.

Kouzes, J.M. and Posner, B.Z. 1995. The leadership challenge. San Francisco: Jossey-Bass.

Lao Tzu, 600 B.C. The Tao of power. Translation by R.L.Wing of Lao Tzu's Tao Te Ching, 2001. New York: Broadway Books.

Mallonee, J.D. 1976. Introduction to business dynamics. Boston: Holbrook Press.

Mandela, N.R. 1997. Long walk to freedom. London: Abacus.

Parry, K.W. \& Proctor-Thomson, S.B. 2002. 'Perceived integrity of transformational leaders in organizational settings', Journal of Business Ethics, 35:75-96.

Posner, B.Z. \& Schmidt, W.H. 1992. 'Values and the American manager: An update updated', California Management Review, Spring: 80-94.

Robinson, D. 1990. 'Cerebral plurality and the unity of self. In Robinson, D. (Ed.). The mind. New York: Oxford University Press.

Rorty, R. 1999. Philosophy and social hope. Harmondsworth: Penguin Books.

Rosenwald, G.C. \& Ochberg, R.L. (Eds.). 1992. Storied lives: The cultural politics of self-understanding. New Haven: Yale University Press.

Rubin, A. \& Babbie, E. 2001. Research methods for social work. Pacific Grove, CA: Books/Cole
Rumi, J. 1988. This longing. Translated by Barks, C. \& Moyne, J. 1988. Putney: Threshold Books.

Scheibe, K.E. 1995. Self studies:Tthe psychology of self and identity. Westport: Praeger.

Schlenker, B. \& Darby, B. 1981. 'The use of apologies in social predicaments', Social Psychology Quarterly, 44(3): 271-278.

Schmidt, W.M. \& Posner, B.Z. 1982. Managerial values and expectations: The silent power in personal and organizational life. New York: AMACOM.

Strauss, A.L. \& Corbin, J. 1990. Basics of qualitative research: Grounded theory, procedures and techniques. Newbury Park: Sage.

Torbert, W.R. 1991. The power of balance: Transforming self, society, and scientific inquiry. Newbury Park: Sage.

Trevino, L.K., Brown, M. \& Hartman, L.P. 2003. 'A qualitative investigation of perceived executive ethical leadership: Perceptions from inside and outside the executive suite', Human relations, 56(1): 5-37.

Von Krosigk, B.C. 2000. 'Exploring forgiveness: A narrative approach to stories of hurt'. Unpublished master's dissertation, UNISA, Pretoria.

Von Krosigk, B.C. 2004. 'Facilitating forgiveness: An NLP approach to forgiving'. Unpublished doctoral thesis. Unisa: Pretoria.

Yukl, G. 2002. Leadership in organizations, $5^{\text {th }}$ Edition. Upper Saddle River, NJ: Prentice Hall. 